\title{
Partial polymerase gene sequence, phylogeny and RT-PCR diagnostic assay for Datura yellow vein nucleorhabdovirus
}

\author{
R. G. Dietzgen • E. R. Tan • A. H. S. Yong • C.-W. A. Feng
}

Received: 13 November 2012 / Accepted: 7 December 2012 / Published online: 19 December 2012

(C) Australasian Plant Pathology Society Inc. 2012

\begin{abstract}
Partial (c. 0.25 and $1.1 \mathrm{~kb}$ ) nucleotide sequences of the L polymerase gene of Datura yellow vein virus (DYVV) were obtained using two sets of degenerate oligonucleotide primers. This is the first sequence information for this virus. Phylogenetic analysis of the conserved L gene sequence with those of other plant rhabdoviruses showed that DYVV is most closely related to Sonchus yellow net virus and confirmed its taxonomic placement in the genus Nucleorhabdovirus. DYVV strains isolated from Datura stramonium and Thungergia alata, respectively, were $97.2 \%$ identical in nucleotide sequence across a $251 \mathrm{nt}$ region of the $\mathrm{L}$ gene. DYVV-specific primers were designed and a diagnostic RT-PCR assay developed and validated.
\end{abstract}

Keywords Degenerate primers $\cdot$ Rhabdovirus $\cdot$ Thunbergia alata $\cdot$ Datura stramonium $\cdot$ Virus detection

\section{Introduction}

Rhabdoviruses have a non-segmented negative-sense, single stranded RNA genome of $11-15 \mathrm{~kb}$ and encode at least five proteins: nucleoprotein $(\mathrm{N})$, phosphoprotein $(\mathrm{P})$, matrix protein $(\mathrm{M})$, glycoprotein $(\mathrm{G})$ and large polymerase $(\mathrm{L})$ in the conserved order 3'-N-P-M-G-L-5' (Dietzgen et al. 2011). Plant-adapted rhabdoviruses also encode at least one

R. G. Dietzgen $(\bowtie)$

Centre for Plant Science, Queensland Alliance for Agriculture and Food Innovation, The University of Queensland,

St. Lucia, Qld 4072, Australia

e-mail: r.dietzgen@uq.edu.au

R. G. Dietzgen · E. R. Tan • A. H. S. Yong • C.-W. A. Feng School of Chemistry and Molecular Biosciences,

The University of Queensland, St. Lucia, Qld 4072, Australia additional protein between the $\mathrm{P}$ and $\mathrm{M}$ genes that is thought to be involved in cell-to-cell movement (Jackson et al. 2005).

Datura yellow vein virus (DYVV) was isolated in Queensland, Australia from Datura stramonium with symptoms of vein yellowing, leaf distortion and reduced leaf size. Bacilliform virions $(50-55 \times 150-155 \mathrm{~nm})$ accumulated in the perinuclear space of infected cells and bullet-shaped particles measuring $77 \times 166 \mathrm{~nm}$ were seen in negatively-stained sap preparations (Thomas and Dietzgen 1991). The virus could be graft-transmitted to tomato, tobacco and eggplant, but no hosts for mechanical transmission and no insect vectors were found. Purified DYVV particles contained four structural proteins with molecular weights of approximately 78, 47, 41 and $36 \mathrm{kDa}$. The $78 \mathrm{kDa}$ protein was identified as the $G$ protein, since it was glycosylated. DYVV was serologically distinct from 11 other rhabdoviruses belonging to either genus of plant-adapted rhabdovirus (Thomas and Dietzgen 1991). A strain of this virus, DYVV-T was isolated from black-eyed Susan (Thunbergia alata) with symptoms of vein yellowing, vein clearing and leaf distortion (Dietzgen et al. 1992). Virions had similar morphology and size to those of the Datura strain. Purified preparations of DYVV-T contained four major proteins that were comparable in size to those of DYVV-D and the two largest proteins reacted strongly with antiserum to DYVV-D (Dietzgen et al. 1992).

DYVV is a distinct nucleorhabdovirus based on particle morphology, nuclear site of replication, physico-chemical properties, serology and size of its major proteins (Thomas and Dietzgen 1991). However, due to a lack of sequence information, its taxonomic classification has not been validated and nucleic acid based diagnostic assays have not been available. This paper provides the first sequence 
information for DYVV, confirms its classification as a nucleorhabdovirus and describes the design and use of diagnostic primers to detect the virus in infected plants.

\section{Materials and methods}

Virus source

Young leaves with vein yellowing and leaf distortion symptoms were collected from a naturally DYVV-infected $T$. alata vine growing at Indooroopilly Plant Research Centre in Brisbane, Australia and stored at $-80{ }^{\circ} \mathrm{C}$ until RNA extraction. DYVV from $D$. stramonium previously purified as described by Thomas and Dietzgen (1991) and diluted 1:1 in glycerol was stored at $-20{ }^{\circ} \mathrm{C}$. The two strains of DYVV from T. alata (Dietzgen et al. 1992) and D. stramonium (Thomas and Dietzgen 1991) are referred to here as DYVV-T and DYVV-D, respectively.

\section{RNA extraction}

Total RNA was extracted from DYVV-infected $T$. alata leaves and Lettuce necrotic yellows virus (LNYV)-infected Nicotiana glutinosa leaves using the RNeasy Plant Mini kit (Qiagen) and RLT buffer according to the manufacturer's instructions. RNA was eluted in RNase-free water and stored in aliquots at $-80^{\circ} \mathrm{C}$. A purified DYVV-D preparation was treated by addition of proteinase $\mathrm{K}$ to $50 \mu \mathrm{g} / \mathrm{ml}$ and sodium dodecyl sulphate to $0.1 \%(\mathrm{w} / \mathrm{v})$ and incubated for $30 \mathrm{~min}$ at $37^{\circ} \mathrm{C}$. RNA was extracted sequentially with equal volumes of phenol saturated with $0.1 \mathrm{M}$ Tris-HCl pH 8.0, phenol:chloroform:isoamylalcohol (25:24:1), then chloroform:isoamylalcohol (24:1). Between each extraction step the phases were separated by centrifugation. RNA was precipitated from the final aqueous phase with ethanol and stored at $-80^{\circ} \mathrm{C}$.

\section{RT-PCR using degenerate primers}

The Superscript III One-step RT-PCR system with Platinum Taq DNA polymerase (Invitrogen) and primers Rhab F (5'GGATMTGGGGBCATCC-3') and Rhab R (5'GTCCABCCYTTTTGYC-3') were used. They were designed to amplify conserved blocks I and III of the rhabdovirus L gene polymerase motif with an expected $\sim 900$ bp amplicon (Lamprecht et al. 2008, 2010). Total RNA was reverse transcribed at $37{ }^{\circ} \mathrm{C}$ for $60 \mathrm{~min}$ after incubation with the primers at $55^{\circ} \mathrm{C}$ for $5 \mathrm{~min}$. PCR amplification was $94{ }^{\circ} \mathrm{C}$ for $2 \mathrm{~min}$, followed by 5 cycles of $94^{\circ} \mathrm{C}$ for $30 \mathrm{~s}, 37^{\circ} \mathrm{C}$ for $30 \mathrm{~s}$, and $68^{\circ} \mathrm{C}$ for $90 \mathrm{~s}$ followed by 35 cycles of $94{ }^{\circ} \mathrm{C}$ for $30 \mathrm{~s}$, $50{ }^{\circ} \mathrm{C}$ for $30 \mathrm{~s}$ and $68{ }^{\circ} \mathrm{C}$ for $90 \mathrm{~s}$ and a final extension at $68{ }^{\circ} \mathrm{C}$ for $10 \mathrm{~min}$. PCR products were analysed on $1 \%$ agarose/tris-borate-EDTA (TBE) gels.
A two-step RT-PCR protocol was used for newly designed primers RhabdoL.4F (5'-GAYTTYRIIAARTGGAA-3') and RhabdoL.5R (5'-AYIGTCCAISCYTTYTG-3') to yield a $\sim 250 \mathrm{bp}$ amplicon. The primers were designed from the consensus amino acid sequence of a ClustalW multiple sequence alignment of the rhabdovirus $\mathrm{L}$ protein polymerase domain of LNYV, Maize mosaic virus (MMV), Maize fine streak virus (MFSV), Northern cereal mosaic virus (NCMV), Rice yellow stunt virus (RYSV), Sonchus yellow net virus (SYNV), Strawberry crinkle virus (SCV) and Taro vein chlorosis virus (TaVCV). Redundancy was minimized by inclusion of inosine. Random hexamers were used to prime firststrand cDNA synthesis using Superscript II reverse transcriptase (Invitrogen). PCR cycling parameters were $94{ }^{\circ} \mathrm{C}$ for $4 \mathrm{~min}$, followed by 30 cycles of $94{ }^{\circ} \mathrm{C}$ for $30 \mathrm{~s}, 41^{\circ} \mathrm{C}$ for $30 \mathrm{~s}, 72^{\circ} \mathrm{C}$ for $1 \mathrm{~min}$ and one cycle of $72{ }^{\circ} \mathrm{C}$ for $7 \mathrm{~min}$. PCR products were analysed by agarose gel electrophoresis.

\section{Cloning and sequencing}

PCR amplicons were gel-purified using QIAEX II gel extraction kit (Qiagen), ligated into pCR4-TOPO (Invitrogen) and transformed into chemically-competent Escherichia coli. Colonies were screened by PCR and DNA was analysed using BigDye Terminator 3.1 chemistry (Applied Biosystems) by capillary sequencing at the Australian Genome Research Facility (AGRF, Brisbane, Australia) using M13 forward and reverse primers. Raw sequence data was edited manually, primer sequence excluded and aligned using Sequencher 4.8 (Gene Codes) and Geneious 5.6 (Biomatters Ltd.) software packages.

\section{Sequence analysis}

Sequences were initially analysed through similarity search by basic local alignment search tool (BLAST). Alignments with other nucleotide sequences extracted from Genbank were done using Clustal W. Phylogenetic trees were constructed using the Tamura-Nei genetic distances model (Tamura et al. 2007) and Neighbor-joining method (Saitou and Nei 1987) in Geneious 5.6 software.

\section{Primer design and diagnostic RT-PCR}

Specific primers were designed from the $\sim 1,000 \mathrm{bpL}$ gene sequence using Primer-Blast (www.ncbi.nlm.nih.gov/tools/ primer-blast). Primers DL1F (5'-GCCAGACCATTAGTGT CCACGCC-3') and DL1R (5'-ACAGCGTCAACCTGGC AACG-3') were designed to yield a 190 bp amplicon. Superscript III One-step RT-PCR system with Platinum Taq DNA polymerase was used with the following cycling parameters: $50{ }^{\circ} \mathrm{C}$ for $30 \mathrm{~min}, 94^{\circ} \mathrm{C}$ for $2 \mathrm{~min}, 40$ cycles of $94{ }^{\circ} \mathrm{C}$ for $15 \mathrm{~s}, 51^{\circ} \mathrm{C}$ for $30 \mathrm{~s}, 68^{\circ} \mathrm{C}$ for $30 \mathrm{~s}$, and $68^{\circ} \mathrm{C}$ for 
5 min. Temperature gradient RT-PCR was done in a PalmCycler (Corbett Research) using a annealing temperature gradient from $45{ }^{\circ} \mathrm{C}$ to $60{ }^{\circ} \mathrm{C}$. PCR products were analysed on $1.2 \%$ agarose/tris-borate-EDTA (TBE) gels.

\section{Results}

DYVV L gene fragment amplified with RhabdoL.4F/5R primers

A PCR product of $\sim 250 \mathrm{bp}$ was amplified by PCR of random primed cDNA from RNA derived from DYVV-D and DYVV-T, and from LNYV-infected N. glutinosa used as control (data not shown). The $\mathrm{L}$ gene fragment from both DYVV strains was cloned and sequenced. The DYVV sequence including the primers was 251 nucleotides long for both strains. A nucleotide blast search through the National Center for Biotechnology Information (NCBI) identified the $\mathrm{L}$ gene sequence of the nucleorhabdovirus SYNV as closest match with $65 \%$ sequence identity and an E-value of 0.002 across the fragment. Alignment of the partial L gene nucleotide sequences of the DYVV-D and -T strains showed that they were $97.2 \%$ identical with seven differences; two in the region of the forward degenerate primer (T-C in position 3 and G-A in position 12), three in the region of the reverse degenerate primer (G-A in position 240, C-G in position 242 and G-A in position 249) and two outside the primer regions (T-C in position 88 and G-A in position 157). None of the nucleotide changes resulted in stop codons and the $\mathrm{L}$ gene open reading frame was maintained in both strains. Only the nucleotide changes at positions 157 and 240 will result in changes in the amino acid sequence, alanine vs threonine and alanine vs glycine, respectively.

DYVV L gene fragment amplified with Rhab F/R primers

An amplicon of $\sim 1,100 \mathrm{bp}$ was obtained following RT-PCR of total RNA from DYVV-infected $T$. alata using primer pair Rhab F and Rhab R. The 1,072 nt partial sequence of the DYVV L gene was lodged in Genbank with accession number JX843415. Blastn and Blastx searches showed that sequences were most similar to known rhabdovirus polymerase sequences. The deduced partial polymerase sequence of 356 amino acids was $66 \%$ identical to that of SYNV polymerase with an E-value of $4 \mathrm{e}^{-156}$.

Phylogenetic analysis of DYVV L gene sequence

Comparison of the nucleotide sequence of the DYVV L gene with the corresponding partial sequences from 12 other plant rhabdoviruses showed that DYVV was most similar to Sonchus yellow net virus (SYNV) with a $63 \%$ sequence identity in the 1,072 nucleotide $\mathrm{L}$ gene region analysed. The phylogenetic tree placed the plant rhabdoviruses into two main clades which corresponded to the two recognized genera of plant-adapted rhabdoviruses, Cytorhabdovirus and Nucleorhabdovirus (Fig. 1). DYVV clustered with SYNV and separated from the other members within the nucleorhabdoviruses clade.

\section{Diagnostic primers for DYVV}

Primers for detection of DYVV in plant tissue were designed from the available partial $\mathrm{L}$ gene sequence and used in one-step RT-PCR yielding a 190 bp product. The optimal annealing temperature determined by $45{ }^{\circ} \mathrm{C}$ to $60{ }^{\circ} \mathrm{C}$ temperature gradient PCR was $52{ }^{\circ} \mathrm{C}$ (data not shown). A 5-fold dilution series of total RNA extracted from DYVV-infected T.alata allowed gel-based detection of the diagnostic amplicon even at a dilution of $1 / 625$, but stronger bands were obtained up to a $1 / 125$ dilution. The diagnostic assay was evaluated using leaves from T.alata collected from plants growing in two locations near the university. All leaves with characteristic virus symptoms as well as non-symptomatic leaves from these plants were positive for DYVV when extracted total RNA was tested neat or diluted $1 / 1,000$.

\section{Discussion}

Rhabdoviruses include many important pathogens of plants and animals with a shared morphology and genome organization (Dietzgen et al. 2011). This paper provides the first sequence information for DYVV, a plant-adapted rhabdovirus from Australia. Based on this sequence the taxonomic classification of DYVV as a nucleorhabdovirus was confirmed and a diagnostic assay was developed for its sensitive detection by RT-PCR. This initial sequence information and molecular diagnostic tool can be expected to assist in future more detailed biological and molecular characterization of DYVV and to contribute to better understanding of plant-adapted rhabdoviruses and their evolution.

Using degenerate primers designed from conserved sequences of the L polymerase gene, a $\sim 250 \mathrm{bp}$ DNA fragment was amplified from RNA of both known strains, DYVV-D and DYVV-T (Thomas and Dietzgen 1991; Dietzgen et al. 1992). The nucleotide sequence divergence between the DYVV strains across this short region of the $\mathrm{L}$ gene was $2.8 \%$, which is similar to the $2 \% \mathrm{~L}$ gene fragment sequence diversity observed between isolates within subgroups of Strawberry crinkle cytorhabdovirus (SCV) 
Fig. 1 Unrooted neighborjoining tree showing relationship of the 1027 nucleotide partial $\mathrm{L}$ gene sequence of Datura yellow vein virus (DYVV) and corresponding sequences of other plant-adapted rhabdoviruses. The viruses and their accession numbers are: Barley yellow striate mosaic virus (BYSMV; FJ665628), Lettuce yellow mottle virus (LYMoV; EF687738), Lettuce necrotic yellows virus (LNYV; NC_007642), Maize fine streak virus (MFSV; AY618417), Maize Iranian mosaic virus (MIMV; DQ186554), Maize mosaic virus (MMV; AY618418), Northern cereal mosaic virus (NCMV; NC_002251), Potato yellow dwarf virus (PYDV; GU734660), Rice yellow stunt virus (RYSV; NC_003746), Sonchus yellow net virus (SYNV; L32603), Strawberry crinkle virus (SCV; AY250986), Taro vein chlorosis virus (TaVCV; AY674964). Branch lengths are proportional to genetic distances between sequences. The bar represents the number of nucleotide changes per site

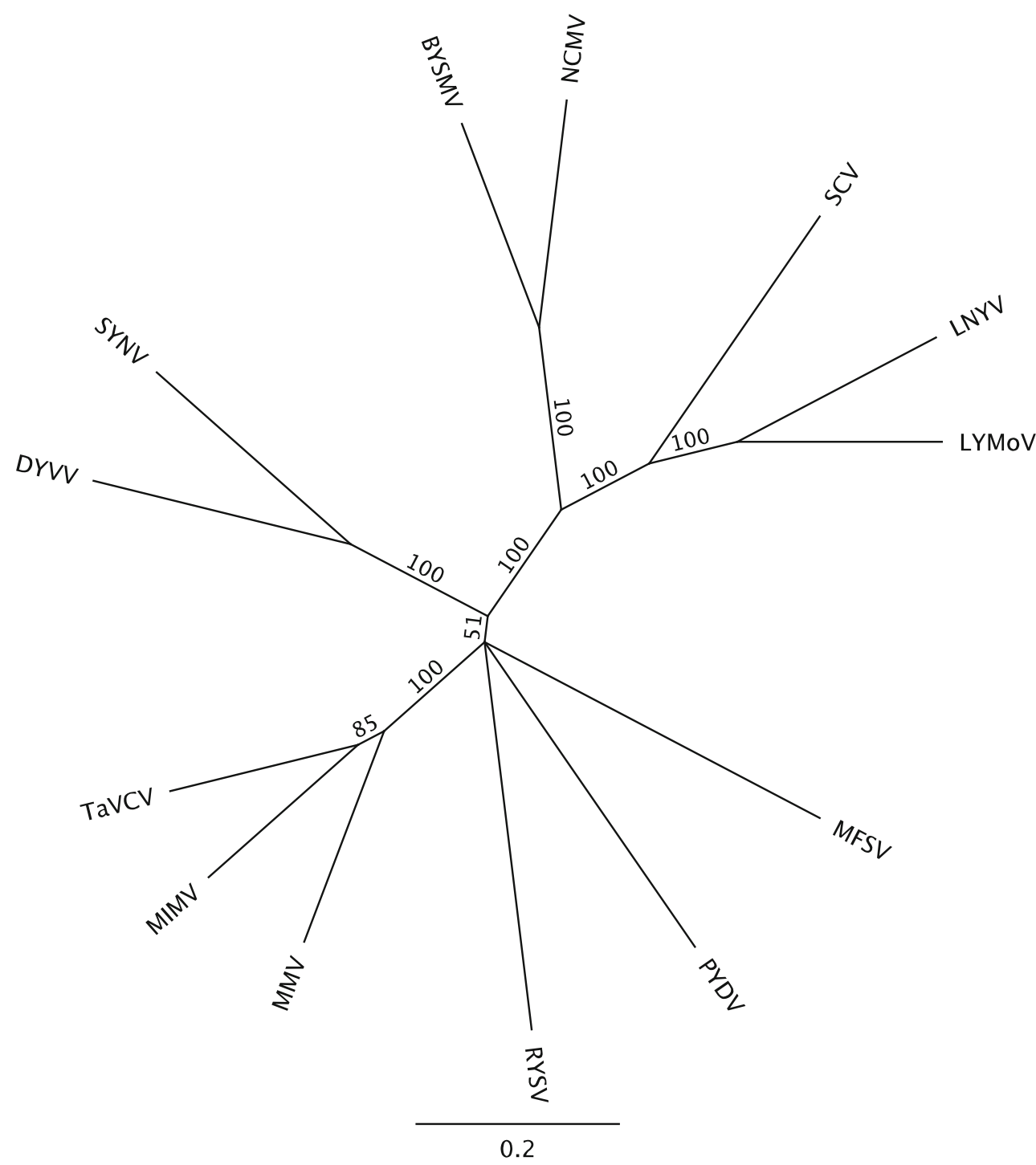

(Klerks et al. 2004). On the other hand, nucleotide sequence diversity of up to $27.4 \%$ was observed within a $\sim 1 \mathrm{~kb}$ fragment of the L polymerase gene of Taro vein clearing nucleorhabdovirus among 20 isolates collected in Pacific Island communities, but some isolates from the same country varied by no more than $3 \%$ (Revill et al. 2005). These degenerate primers were also shown to amplify a corresponding $\mathrm{L}$ gene sequence from Lettuce necrotic yellows cytorhabdovirus, one of the viral sequences used in the alignment to design the primers. However, a drawback of using these primers is the short amplicon size, compared to published alternative $\mathrm{L}$ gene primers such as those devised by Lamprecht et al. $(2008,2010)$ that yielded $\mathrm{a} \sim 1.1 \mathrm{~kb}$ amplicon which was more suitable for diagnostic primer design, sequence comparisons and phylogenetic analysis.

Based on the $\sim 1.1 \mathrm{~kb}$ sequence of the $\mathrm{L}$ gene from DYVV-T, oligonucleotide primers were designed and tested for the detection of DYVV in infected plant samples. The diagnostic RT-PCR assay was sensitive and reproducible and will also be useful to identify potential insect vectors of DYVV. Diagnostic RT-PCR assays based on conserved rhabdovirus $\mathrm{L}$ gene sequences have also been developed and applied for detection of SCV and Raspberry vein chlorosis virus in both infected leaves and in aphid vectors (Posthuma et al. 2002; McGavin et al. 2011).

The $\mathrm{L}$ polymerase gene of rhabdoviruses has proven to be a useful region to infer phylogenetic relationships among this diverse family of viruses that infect plants, fish and mammals (Bouhry et al. 2005; Kuzmin et al. 2009). This was also the case for DYVV which appears most closely related to SYNV among the plant rhabdoviruses where sequence information is available. Both viruses clustered within the clade of viruses that are classified in the genus Nucleorhabdovirus, supporting its taxonomic classification based on previous electron microscopic studies that show bacilliform particles accumulating in the perinuclear space of infected cells (Thomas and Dietzgen 1991). 
Acknowledgments We thank the former Queensland Department of Employment, Economic Development and Innovation and the University of Queensland for financial support, Mr R. Mitchell for technical assistance and Dr D. Innes for advice with Geneious software.

\section{References}

Bouhry H, Cowley JA, Larrous F, Holmes EC, Walker PJ (2005) Phylogenetic relationships among rhabdoviruses inferred using the L polymerase gene. J Gen Virol 86:2849-2858

Dietzgen RG, Gowanlock DH, Thomas JE (1992) Purification and identification of a rhabdovirus from Thunbergia alata. J Phytopathol 135:99-106

Dietzgen RG, Calisher CH, Kurath G, Kuzmin IV, Rodriguez LL, Stone DM, Tesh RB, Tordo N, Walker PJ, Wetzel T, Whitfield AE (2011) Family Rhabdoviridae. In: King AMQ, Adams MJ, Carstens EB, Lefkowitz EJ (eds) Virus taxonomy, Ninth Report of the International Committee on Taxonomy of Viruses. Elsevier, Oxford, pp 686-714

Jackson AO, Dietzgen RG, Goodin MM, Bragg JN, Deng M (2005) Biology of plant rhabdoviruses. Annu Rev Phytopathol 43:623-660

Klerks MM, Lindner JL, Vaškova D, Špak J, Thompson JR, Jelkmann W, Schoen CD (2004) Detection and tentative grouping of Strawberry crinkle virus isolates. Eur J Plant Pathol 110:45-52
Kuzmin IV, Novella IS, Dietzgen RG, Padhi A, Rupprecht CE (2009) The rhabdoviruses: biodiversity, phylogenetics, and evolution. Infect Genet Evol 9:541-553

Lamprecht RL, Pietersen G, Kasdorf GGF, Nel LH (2008) Characterisation of a proposed Nucleorhabdovirus new to South Africa. Eur J Plant Pathol 123:105-110

Lamprecht RL, Kasdorf GGF, Stiller M, Staples SM, Nel LH, Pietersen G (2010) Soybean blotchy mosaic virus, a new cytorhabdovirus found in South Africa. Plant Dis 94:1348-1354

McGavin WJ, Cock PJA, MacFarlane SA (2011) Partial sequence and RT-PCR diagnostic test for the plant rhabdovirus Raspberry vein chlorosis virus. Plant Pathol 60:462-467

Posthuma KI, Adams AN, Hong Y, Kirby MJ (2002) Detection of Strawberry crinkle virus in plants and aphids by RT-PCR using conserved L gene sequences. Plant Pathol 51:266-274

Revill P, Trinh X, Dale J, Harding R (2005) Taro vein chlorosis virus: characterization and variability of a new nucleorhabdovirus. J Gen Virol 86:491-499

Saitou N, Nei M (1987) The neighbor-joining method: a new method for reconstructing phylogenetic trees. Mol Biol Evol $4: 406-425$

Tamura K, Dudley J, Nei M, Kumar S (2007) MEGA 4: Molecular Evolutionary Genetics Analysis (MEGA) software version 4.0. Mol Biol Evol 248:1596-1599

Thomas JE, Dietzgen RG (1991) Characterisation of datura yellow vein virus, a newly described rhabdovirus from Australia. Ann Appl Biol 118:339-349 